\title{
EFFECT OF SiC AND GR REINFORCEMENT PARTICLES ON THE STRUCTURE AND FUNCTIONAL PROPERTIES OF COMPOSITE CASTING
}

\begin{abstract}
The aim of the study was to describe the structure of composites based on the AlSi7Mg2Sr0.03 alloy matrix reinforced with $\mathrm{SiC}$ particles added in an amount of $10 \%$ and with a mixture of $\mathrm{SiC}$ and GR particles added in a total amount of $20 \%$. Studies of the composite structure, were carried out by scanning electron microscopy (SEM). Based on the results of chemical analysis in microregions, an increased content of elements such as $\mathrm{Mg}, \mathrm{O}$ and $\mathrm{Si}$ and of the precipitates was observed at the interface. In many places in the examined sample, GR particles formed partly disintegrated conglomerates with well developed boundaries. The effect of the content of particles of the reinforcing phase on the functional properties of the composite was investigated during studies of abrasion. The lowest mass loss of 5,33mg was obtained for the $\mathrm{AlSi} 7 \mathrm{Mg} 2 \mathrm{Sr} 0.03$ alloy reinforced with $10 \% \mathrm{SiC}$ particles.
\end{abstract}

Keywords: Aluminium hybrid composite, microstructure, wear tests

\section{Introduction}

Composites based on the aluminium alloy matrix reinforced with ceramic particles (silicon carbide and/or graphite) offer many additional features as compared to the base alloy without reinforcement. The additional characteristics include high hardness and compressive strength, better resistance to wear and lower coefficient of thermal expansion, all of which predispose the composite materials for use in aerospace, military and automotive applications [1-6]. The increasing interest in this type of materials is dictated by the satisfactory strength-to-density ratio, combined with high tribological properties compared to the alloy matrix without reinforcement. The performance properties of composite products (pistons, bushings, bearings, disks), especially the resistance to wear under friction, depend mainly on the type, size, shape and content of the reinforcing particles [5-9].

When an composite element based on the alloy reinforced with particles of, for example, $\mathrm{SiC}$ is designed to cooperate with another element made of metal, a rapid surface wear due to friction can be expected [10]. One of the possible means to protect the surface against the effect of friction is by the use of lubricant. The lubricant used most commonly is graphite. In places hard to access where the lubricant can not be applied, the composite structure is enriched with particles of graphite (GR) [11-14] or glassy carbon $(\mathrm{Cg})$ [15-18]. As a result of this addition, when the composite is rubbing against a metal part, the effect of self-lubrication is triggered, reducing thereby the wear due to friction. Among the numerous examples of such applications are composite piston assemblies based on an aluminium alloy with hybrid-type $\mathrm{SiC}+\mathrm{Cg}[3,18]$ or $\mathrm{SiC}+$ GR [14] reinforcement.
The aim of this study was to characterize the structure of cast composites based on the AlSi7Mg2Sr0.03 alloy matrix reinforced with $\mathrm{SiC}$ and GR particles and determine the effect of $\mathrm{SiC}$ and GR particle morphology on mass loss during abrasion testing.

\section{Materials and experimental methods}

Tests were carried out on composite pistons produced by casting in semi-technical scale at the Złotecki Ltd. Company $[19,20]$. To prepare a composite suspension, the base AlSi7Mg alloy was used. The alloy after melting at $720^{\circ} \mathrm{C}$ was refined with argon jet flowing at a rate of $21 / \mathrm{h}$. Modification of the chemical composition of alloy matrix was accomplished with AlMg25, AlSr master alloy (Table 1) (Fig 1a). For the composite reinforcing phase, particles of silicon carbide ( $\mathrm{SiC})$ (Fig 1b) and a hybrid mixture of $\mathrm{SiC}+\mathrm{GR}$ were selected (Fig. 1c). The average dimensions of $\mathrm{SiC}$ and GR particles were $38 \mathrm{~mm}$ and $19 \mathrm{~mm}$, respectively.

Pistons were cast from the AlSi7Mg2Sr003 alloy-based composites with 10 vol \% SiC and 10 vol \% SiC +10 vol $\%$ GR. To reveal the macrostructure, castings were cut through the gating system and riser. As a next step, specimens were cut out from the castings and metallographic sections were prepared. The metallographic sections were prepared using abrasive papers and polishing cloth. The process of polishing specimens reinforced with particles of $\mathrm{SiC}$ and $\mathrm{Gr}$ required a significantly longer time than specimens from standard aluminum alloys which were related to numerous problems in structures. The composites were examined under an Olympus GX70 light microscope (LM) and by scanning electron microscopy (SEM)

* INSTITUTE OF NON-FERROUS METALS IN GLIWICE, LIGHT METALS DIVISION, 16 PIESUDSKIEGO STR., 32-050 SKAWINA, POLAND

** SILESIAN UNIVERSITY OF TECHNOLOGY, FACULTY OF MATERIALS ENGINEERING AND METALLURGY, 8 KRASINSKIEGO STR., 40-019 KATOWICE, POLAND

\# Corresponding author: sboczkal@imn.skawina.pl 
Chemical composition of the composite matrix [wt.\%]

\begin{tabular}{|c|c|c|c|c|c|c|c|c|}
\hline \hline & $\mathrm{Si}$ & $\mathrm{Fe}$ & $\mathrm{Cu}$ & $\mathrm{Mn}$ & $\mathrm{Mg}$ & $\mathrm{Ti}$ & $\mathrm{Sr}$ & $\mathrm{B}$ \\
\hline $\mathrm{AlSi} 7 \mathrm{Mg} 2 \mathrm{Sr} 003$ & 9.04 & 0.355 & 0.266 & 0.245 & 2.35 & 0.114 & 0.044 & 0.0011 \\
\hline
\end{tabular}

a)
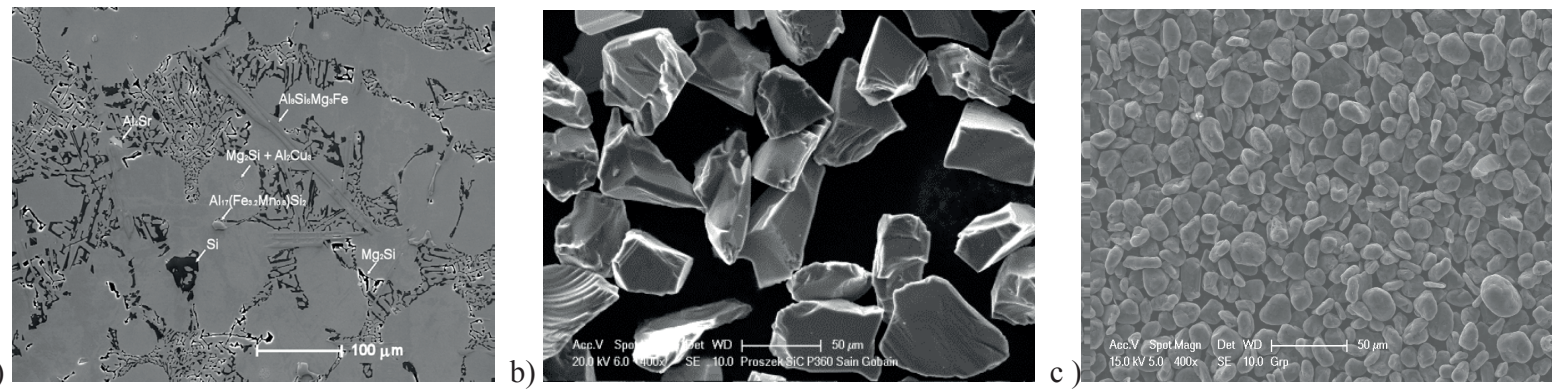

Fig.1 The structure of base materials used for the composite fabrication: a) AlSi7Mg2Sr003 alloy matrix, b) SiC particles, and c) GR particles.

with chemical analysis in microregions (EDS) using Inspect F50 and Philips XL30 microscopes. Abrasion resistance tests were performed on a Taber Abraser 5155 device monitoring the mass loss after 1000 and 5000 abrasion cycles on 10 samples of the selected material. For both composites, abrasion tests were done under the same conditions ((H18 abrasive wheels (DB 09A1) load of 500g, 70\% suction force, rotating speed of $60 \mathrm{rev} / \mathrm{min})$. On each composite, tests were performed for statistical purposes using 10 specimens taken from different cast pistons.

\section{Results and discussion}

Studies were carried out on pistons cast samples from the AlSi7Mg2Sr0.03/SiC and A1Si7Mg2Sr0.03/SiC + GR composites. In both composites, SiC particles were distributed evenly in the examined area of the sample (Fig. 2). Occasionally, small cracks were visible probably due to the technique by which the metallographic section was prepared. The examinations showed an even distribution of graphite in the hybrid composite. Because there were no clusters of particles, and the distances between particles were arranged in similar intervals, thus it can be concluded that both studied composites were homogeneous.

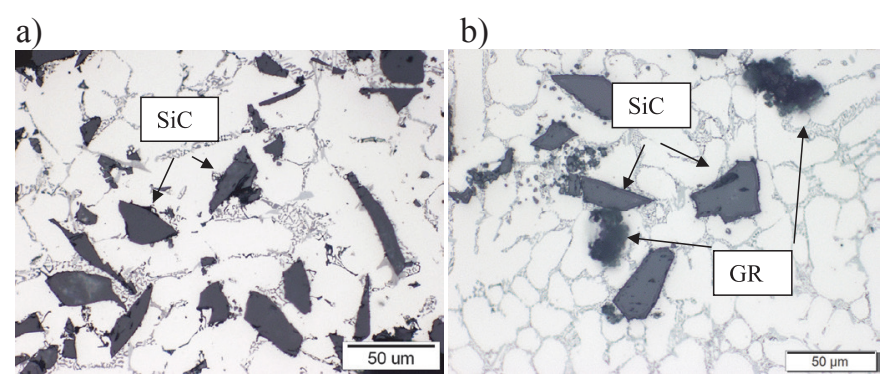

Fig. 2 The structure of composites: a) AlSi7Mg2Sr0.03/SiC and b) AlSi7Mg2Sr0.03/SiC+GR

The characteristic shape of particles and of the $\mathrm{SiC} /$ graphite particles - matrix interface was examined by highresolution scanning electron microscopy. The intefaces between $\mathrm{SiC}$ particles and composite matrix were of an angular shape with distinctly drawn outlines (Fig. 3). In most cases, the particles were well embedded in the matrix and their boundaries were angular in shape. Occasionally, some places in the particle-matrix interface showed the presence of silicon eutectic, brittle iron phases, $\mathrm{Mg}_{2} \mathrm{Si}$ compounds and small loose fragments, which were probably formed during the specimen preparation. Linear chemical analysis of the particle-matrix interface has revealed, in addition to $\mathrm{Al}$ and $\mathrm{Si}$ also the presence of $\mathrm{Mg}$. In the direction towards the particle and ahead of the particle, a high content of $\mathrm{Mg}$ was reported. The presence of $\mathrm{Sr}$ was not traced in the particlematrix interface. $\mathrm{Mg}$ and $\mathrm{Sr}$ were added to the AlSi alloy to improve wetting of the ceramic particles in aluminium alloy matrix [21]. Own studies done in [22] demonstrated the presence of Al-Mg-O spinel formed in the phase boundary and playing the role of a "bridge" connecting both materials. Moreover, the formation of spinel layer and/or oxides at the $\mathrm{Al} / \mathrm{SiC}$ interface has been described by many authors [2327]. There is a suspicion that in this case formed spinels $\mathrm{Al}-\mathrm{Mg}-\mathrm{O}$ around the $\mathrm{SiC}$ particles but during the casting process were detached from the border and have moved to form small (white imaged by SEM) inclusions around the particles (Fig. 3 and 4).

Graphite particles were characterized by a well developed boundary (Fig. 5). Their shape did not resemble a solid body but rather a partially smeared inclusion. The smearing effect was caused by the technique of the metallographic section preparation. The metallographic sections were prepared using abrasive papers and polishing cloth. The process of the metallographic section preparation also contributed to the occurrence of voids from which, most probably, the particles of both $\mathrm{SiC}$ and GR "fell out". The linear analysis of the distribution of elements in the GR particle-matrix interface showed a pronounced increase in the $\mathrm{Si}$ content and a small increase only in the $\mathrm{Mg}$ and $\mathrm{O}$ content. The increased silicon content ahead of the phase boundary might be due to the presence of Si lamellae included in the composition of the AlSi alloy eutectic. Small increase in the $\mathrm{Mg}$ and $\mathrm{O}$ content proves low degree of enrichment of the GR particle-matrix interface in magnesium and/or magnesium oxides. No increase of the 
Sr content was traced in the phase boundary with either $\mathrm{SiC}$ or GR particles.
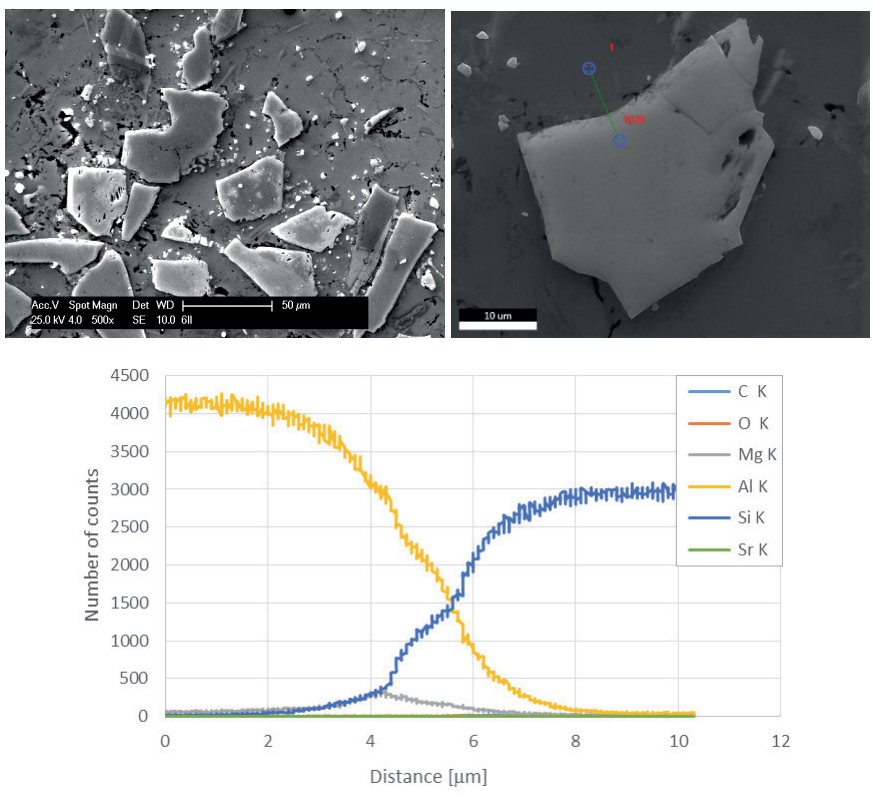

Fig. 3 The structure of AlSi7Mg2Sr0.03/SiC composite with linear chemical analysis

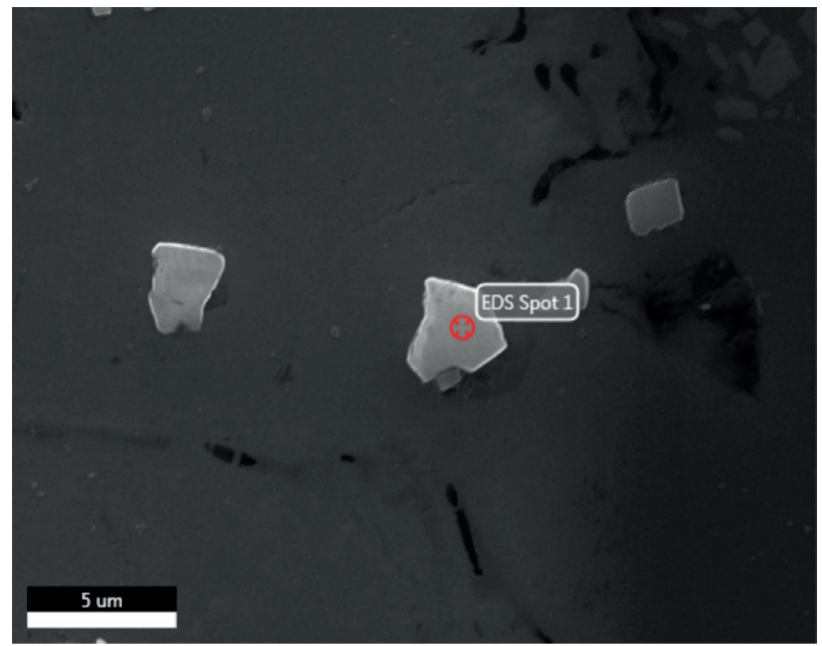

\begin{tabular}{|c|c|c|}
\hline Element & Weight $\%$ & Atomic \% \\
\hline $\mathrm{C} \mathrm{K}$ & 13.28 & 25.81 \\
\hline $\mathrm{O} \mathrm{K}$ & 0.63 & 0.91 \\
\hline $\mathrm{MgK}$ & 0.97 & 0.93 \\
\hline $\mathrm{AlK}$ & 47.21 & 40.84 \\
\hline $\mathrm{SiK}$ & 37.92 & 31.51 \\
\hline
\end{tabular}

Fig. 4 Small inclusions around $\mathrm{SiC}$ particles

Abrasion resistance was examined by Taber abrasion test, which showed different mass loss values for the base alloy matrix and composite material (Table 2, Fig. 6). The average mass loss after 1000 cycles was $5.33 \mathrm{mg}$ for the composite containing $10 \% \mathrm{SiC}$, which was $6,2 \mathrm{mg}$ lower of the average mass loss (11,5 mg) obtained for a hybrid composite with $10 \%$ $\mathrm{SiC}$ and $10 \%$ GR. Compared to the base AlSi7Mg2Sr0.03 alloy $(29,5 \mathrm{mg})$, the mass loss in the composite with $10 \% \mathrm{SiC}$ was 24,2 mg lower, while in the hybrid composite it was 18 mg lower. After 5000 cycles, the mass loss was observed to increase for the base alloy matrix and both composites tested. The mass loss assumed the highest value in the base alloy and amounted to $122.9 \mathrm{mg}$. In the tested composites after 5000 cycles, the mass loss was higher compared to 1000 cycles. In a composite with $10 \% \mathrm{SiC}$, the mass loss was $13.6 \mathrm{mg}(8,3 \mathrm{mg}$ higher compared to 1000 cycles), while for a hybrid composite it was $19.9 \mathrm{mg}$ (8,4 $\mathrm{mg}$ higher compared to 1000 cycles).
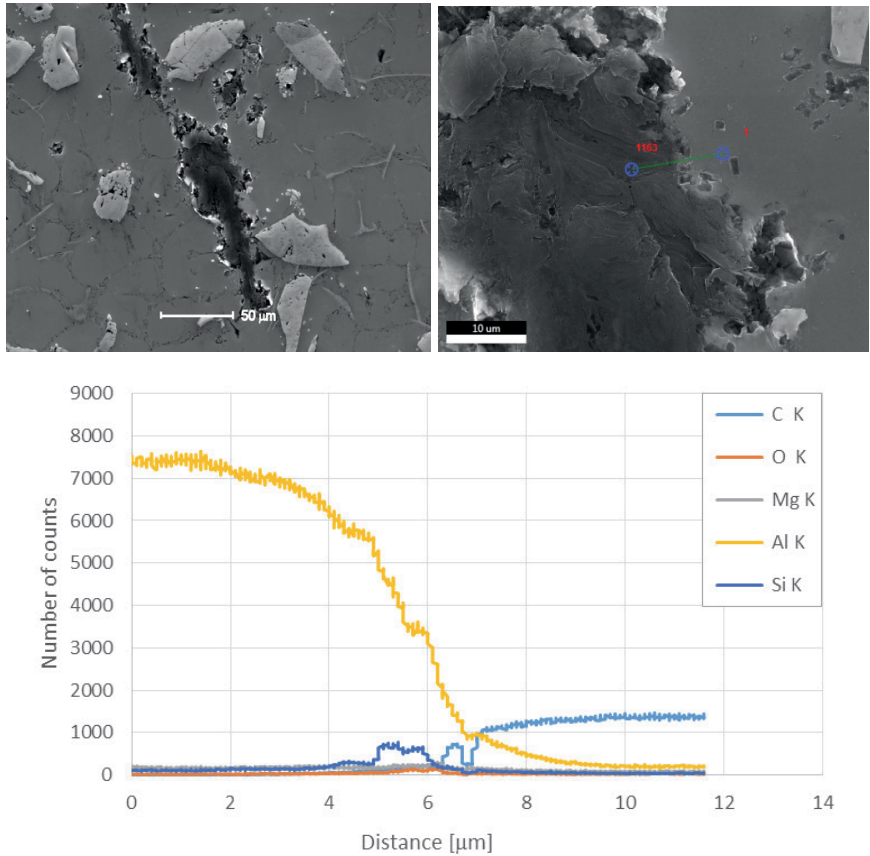

Fig. 5. The structure of AlSi7Mg2Sr0.03/SiC + GR composite with linear chemical analysis

As a result of abrasion test made on 10 samples of each material, the average mass loss and standard deviation were calculated. Analysis of the results showed differences in the standard deviation obtained for each material (Fig. 6). The lowest scatter of the results of the mass loss measurements after 1000 cycles was observed in the hybrid composite. With the number of cycles raised from 1000 to 5000, an increased scatter of the results has occurred in the tested composites. After 5000 cycles, the scatter of the results was the lowest in the composite containing $10 \% \mathrm{SiC}$ in compare to analysed materials. The higher scatter of the results in the tested materials after 5000 cycles was probably due to the presence of

TABLE 2

The average mass loss obtained in Taber abrasion test

\begin{tabular}{|c|c|c|c|}
\hline \hline Cycles $\backslash$ Material & AlSi7Mg2Sr0.03 & AlSi7Mg2Sr0.03/SiC & AlSi7Mg2Sr0.03/SiC+GR \\
\hline 1000 & $29,5 \mathrm{mg} \pm 7,6 \mathrm{mg}$ & $5,3 \mathrm{mg} \pm 1,1 \mathrm{mg}$ & $11,5 \mathrm{mg} \pm 0,8 \mathrm{mg}$ \\
\hline 5000 & $122,9 \mathrm{mg} \pm 10,7 \mathrm{mg}$ & $13,6 \mathrm{mg} \pm 3,5 \mathrm{mg}$ & $19,9 \mathrm{mg} \pm 4,7 \mathrm{mg}$ \\
\hline
\end{tabular}


two factors, the first one associated with the abrasion process, i.e. maintaining a uniform pressure and disposal of the wear products, and the second related to material homogeneity.

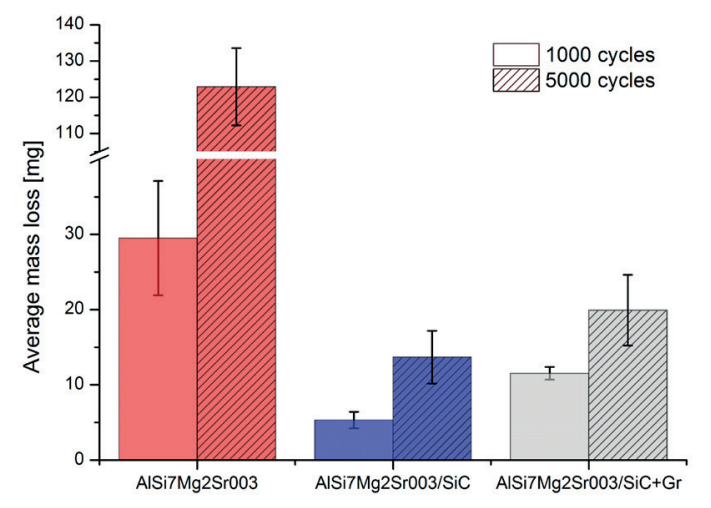

Fig. 6 Mass loss observed in the tested materials after 1000 cycles and 5000 cycles with standard deviation marked in the diagram. a)

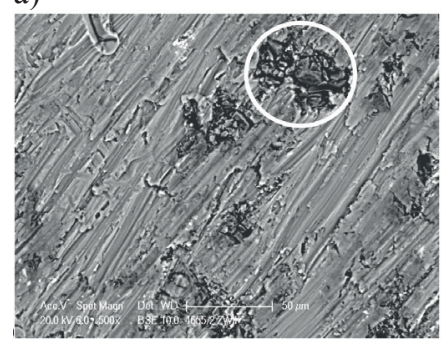

b)

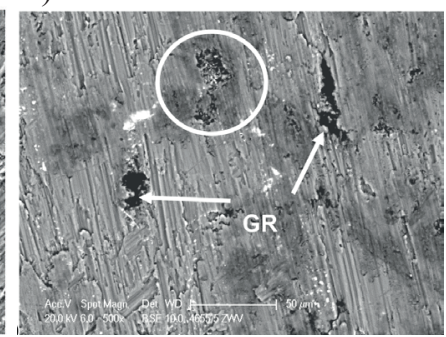

Fig. 7 The surface of composites after abrasion test (5000 cycles): (a) AlSi7Mg2Sr0.03/SiC and (b) AlSi7Mg2Sr0.03/SiC + GR. White circles indicate the crushed $\mathrm{SiC}$ particles.

Subsequently, an analysis of the sample surface after the abrasion test was carried out (Fig. 7). Visible in the photograph (Fig. 7a) topography has wider and deeper furrows in comparison to the topography shown in Figure 7b. More detailed examinations also show the effect of particle disintegration taking place in this particular case, and crushed particles penetrating the matrix material with their angular and sharply outlined edges. The process of abrasion proceeds in this case with more difficulty because crushed particles are moving along the plastic surface of the matrix, leaving deep furrows. The situation was different in the case of a hybrid composite containing $10 \% \mathrm{SiC}$ and $10 \% \mathrm{GR}$. The furrows were shallow probably due to the presence of graphite, which facilitated sliding over the abraded surface. In measuring the average width of furrows on SEM it shows that the composite with $10 \% \mathrm{SiC}$ have wider furrows which were $3.14 \mu \mathrm{m}$ than in the hybrid composite wherein has been found furrows with a width of $1.35 \mu \mathrm{m}$. Graphite in the structure of the composite reinforced with $\mathrm{SiC}$ tended to penetrate the crushed SiC particles, acting as a "lubricant". Figure 8 shows a particle of $\mathrm{SiC}$ smeared with graphite after the preparation of a metallographic section as confirmed by performing point chemical analysis on EDS in the lubricating area on $\mathrm{SiC}$ particle and on the particle. The fine particles of $\mathrm{SiC}$ tried to penetrate the alloy matrix but

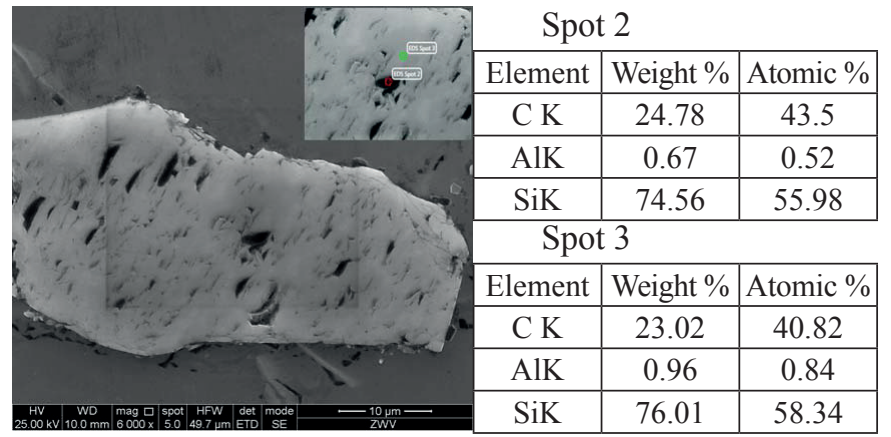

Fig. 8 Graphite-smeared $\mathrm{SiC}$ particle present in the A1Si7Mg2Sr0.03/ $\mathrm{SiC}+\mathrm{GR}$ hybrid composite

having much lower force of adhesion fell out and under the pressure of the clamping device were crushed even more, leaving only minor scratches on the metal surface.

Therefore, isolated crushed $\mathrm{SiC}$ and GR particles torn out during friction have contributed to more severe mass loss of the composite. From the studies of abrasion carried out in [12] on similar hybrid materials containing $20 \% \mathrm{SiC}$ and $3 \% \mathrm{GR}$ as well as $10 \%$ GR it follows that increasing the graphite content up to $10 \%$ reduces the wear resistance.

\section{Conclusions}

- In the study a comparison was made between two pistons cast from the AlSi7Mg2Sr0.03/SiC and AlSi7Mg2Sr0.03/ $\mathrm{SiC}+\mathrm{GR}$ composite materials. The structure and abrasion wear behaviour of the composites were examined and the following conclusions were drawn:

- $\quad$ Composites based on the A1Si7Mg2Sr0.03 alloy showed a uniform distribution of the $\mathrm{SiC}$ and $\mathrm{SiC}+\mathrm{GR}$ particles in matrix.

- $\quad \mathrm{SiC}$ particles were characterized by polyhedral shapes with sharp edges, while GR particles were more elongated than the granules in base state and showed highly developed matrix interface.

- The AlSi7Mg2Sr0.03/SiC composite was enriched in elements such as $\mathrm{Al}, \mathrm{Si}$ and $\mathrm{Mg}$ at the particle/matrix interface and inside the matrix around $\mathrm{SiC}$ particles, while in the AlSi7Mg2 Sr0.03/SiC + GR composite, the phase boundary was enriched in the particles of elements such as $\mathrm{Al}, \mathrm{Si}, \mathrm{C}, \mathrm{Mg}$ and $\mathrm{O}$.

- It was found that the lowest mass loss during abrasion tests, and hence the best wear resistance was obtained in the AlSi7Mg2Sr0.03/SiC composite.

- The AlSi7Mg2Sr0.03/SiC + GR hybrid composite was characterized by the mass loss of approx. $6,25 \mathrm{mg}$ after both 1000 and 5000 cycles, i.e. higher than the composite reinforced with $\mathrm{SiC}$ particles.

- During the abrasion process, in the composite with $10 \% \mathrm{SiC}$, the crushed $\mathrm{SiC}$ particles were penetrating the matrix material and by moving in the matrix were contributing to the formation of deep furrows. In the hybrid composite with $10 \% \mathrm{SiC}$ and $10 \% \mathrm{GR}$, the surface topography after the abrasion test showed the presence of more shallow furrows, formed by the SiC particles falling out, crushed and then smeared with graphite. 


\section{Acknowledgements}

Studies co-financed by NCBiR within the framework of the Programme for Applied Research Agreement PBS1 / B6 / $13 / 2012$

\section{REFERENCES}

[1] S.V. Prasad, R. Asthana, Tribol. Lett. 17, 445-453 (2004)

[2] B. Mondal, S. Kundu, A.K. Lohar, B.C. Pai B.C, Mat. Sci. Eng. A 498, 37-41 (2008).

[3] M. Dyzia, Solid State Phenomena 176, 49-54 (2011).

[4] S. Golak, Dyzia, M., J. Mater. Sci. Tech. 31(9), 918-922 (2015).

[5] A. Daoud, M.T. Abou El-khair, Tribol. Int. 43 (3), 544-553 (2010).

[6] R.K. Uyyuru, M.K. Surappa, S. Brusethaug, Wear 260, 11-12, 1248-1255 (2006)

[7] J. Wieczorek, Arch. Metal. Mater. 60(1), 111-15 (2014).

[8] P. Kurtyka, N. Rylko, T. Tokarski, A. Wójcicka, A. Pietras, Comp. Struct. 133, 959-967 (2015)

[9] P. Egizabal, A. Romero, A. Torregaray, Analysis of the Solidification and Properties of Plaster Cast Al Based Composites, Arch. Metall. Mater. 57(1), 119-125, (2012).

[10] J. Wieczorek, M. Dyzia, A.J. Dolata, Solid State Phenomena 191, 70-50 (2012).

[11] M. Łągiewka, Z. Konopka, A. Zyska, M. Nadolski; Particles,
Arch. Foundry Eng. 8(3), 59-62 (2008).

[12] W. Ames, A. T. Alpas, Metal. Mater. Trans. A 26, 85-98 (1995).

[13] S. Suresha, B.K. Sridhara, Mater. Design 34, 576-583 (2012).

[14] N.D. Prasant, D.B Venkataraman, IJEST 4(3), 389-395 (2015).

[15] A. Posmyk, H. Wistuba, Arch. Metall. Mater. 56(4), 909-917, (2011).

[16] A. Posmyk, J. Myalski, H. Wistuba, Arch. Metall. Mater.60(4) 2015

[17] A.J. Dolata, J. Wieczorek, Solid State Phenomena 212, 45-48 (2014).

[18] A. Dolata-Grosz, M. Dyzia, J. Śleziona, J. Wieczorek, Arch. Foundry Eng. 7(1), 37-40 (2007).

[19] J. Sleziona, M. Dyzia, A. Dolata-Grosz, J. Wieczorek, PL Patent No. 391006-A1, Polish Patent Office 2011.

[20] A.J. Dolata, M. Dyzia, IOP Conf. Series: Mater. Sci. Eng., 35, DOI. 10.1088/1757-899X/35/1/012020 (2012).

[21] A.J. Dolata, M. Dyzia, Arch. Foundry Eng. 14(1), 135-138 (2014).

[22] A. Dolata-Grosz, Solid State Phenomena 176, 55-62 (2011).

[23] K.N. Braszczyńska, A. Bochenek, A. Zyska, Kompozyty (Composites) 2(4), 157-162 (2002), in polish.

[24] D.J. Lloyd, H. Lagace, A. McLeod, P.L. Morris, Mater. Sci. Eng. A, 10A, 107-73 (1989).

[25] N. Wang, Z. Wang, G.C. Weatherly, Metal. Trans. A, 23A, 1423-1430 (1992).

[26] W.M. Zhong, G. L'Espérance, M. Suéry, Metal. Mater. Trans. A, 26A, (10) 2637-2649 (1995).

[27] Z.P. Luo, Acta Mater., 54, 47-58 (2006). 
